John P. Gabriele

The College of Wooster, Ohio

\title{
LA AUTO-GENERATIVIDAD NARRATIVA EN DON QUIJOTE: PARADIGMA DE UNA CONVENCIÓN LITERARIA POSMODERNA
}

Palabras clave: realidad, ilusión, auto-generatividad, posmodernidad

El mundo que crea Miguel de Cervantes en Don Quijote es textual y contextualmente inestable, construido conforme a un paradigma narrativo propio de la época posmoderna de nuestros días en el cual lo real y lo ilusorio se oponen, se retan, se funden y se confunden persistentemente a lo largo de la novela para sugerir que el arte y la vida son procesos de retextualización y reapropiación esencialmente auto-reflexivos. Se trata de un mundo laberíntico en el cual la realidad y la ilusión son conceptos igualmente autoritarios y tenues al mismo tiempo. Consta decir que la problemática entre lo real y lo ilusorio o el realismo y el idealismo -las innegables piedras angulares de todo estudio sobre el Quijote- no es un tema nuevo en cuanto se refiere al análisis de la novela cervantina. Bien se podría preguntar -y con razón-, ¿qué de nuevo aportaría una lectura de Don Quijote que abarca un estudio de la realidad y la ilusión, una temática harto desarrollada por la crítica cervantina? Algunos contestarían, nada. Sin embargo, un buen número de estudios recientes siguen profundizando la trascendental relación operativa de lo real y lo ilusorio en la novela cervantina y, en particular, dentro del contexto de la posmodernidad (ver, por ejemplo, Beusterien, Dunn, Durán y Fogg, Gabriele, Ramírez, Riley, Tollinchi, Weber).

Individual y colectivamente, estos estudios tienen un doble objetivo. Primero, demuestran que la interacción de lo real y lo ilusorio constituye la lente de acercamiento crítico más perennemente eficaz para seguir indagando la novela de Cervantes. Segundo, sirven para reiterar la perpetua contemporaneidad del Quijote, una novela que está sempiternamente corriente como ha sugerido Álvaro Ramírez (2005: 82). Mi intención en el presente estudio pues, es ofrecer una perspectiva más sobre la sempiterna actualidad de Don Quijote. En específico, me propongo analizar varios episodios ejemplares de la novela para mostrar cómo Cervantes crea una novela que se conforma a uno de los principales objetivos determinantes de la literatura posmoderna de nuestros días, la autogeneratividad.

Ambas la realidad y la ilusión en Don Quijote se crean delante de los ojos de los lectores sin apoyo en el mundo extraliterario. La novela es una obra intertextual e intratextual en el sentido más estricto. «Lo primero en que reparáis de los sonetos, epigramas o elogios que os faltan para el principio», le aconseja el amigo a Cervantes en el prólogo a la primera parte, «se puede remediar en que vos mismo toméis algún trabajo en hacerlos, y después lo podéis bautizar y poner el nombre que quisiéredes, ahijándolos al Preste Juan de las Indias o al Emperador de Trapisonda». «En lo de citar en las márgenes 
los libros y autores de donde sacáredes las sentencias y dichos», continúa el amigo, «no hay más sino hacer de manera que vengan a pelo algunas sentencias o latines que vos sepáis de memoria». En cuanto a las «anotaciones», el amigo da el ejemplo del «gigante Golías», para quien se puede escribir que «fue filisteo a quien el Pastor David mató [...], según se cuenta en el Libro de los Reyes». Para «la citación de los autores [...], el remedio que esto tiene es muy fácil», declara el amigo, «porque no habéis de hacer otra cosa que buscar un libro que los acote todos, desde la A hasta la Z» y poner ese mismo «abecedario [...] en vuestro libro». Esto servirá, concluye, en «dar de improviso autoridad al libro», insistiendo que «no habrá quien se ponga a averiguar si los seguistes o no» (Cervantes, 1970: 1213-1214).

El objetivo de Cervantes en el prólogo es, como bien se sabe, poner en cuestión la autoría de su obra. Al proclamarse "padrastro de Don Quijote» e insistir que no quiere escribir su novela de acuerdo con «la corriente del uso» (1970: 1212), Cervantes pone en marcha una narrativa que acabará con su propia desaparición como el escritor de la novela y la afirmación de ésta como texto que se auto-engendra. Pero también sugiere que el acto creativo es un ejercicio de improvisación y experimentación estética. Los consejos que Cervantes se da a sí mismo mediante el amigo imaginado, el cual representa la conciencia autorial de aquél, es la primera señal que la auto-generatividad se asienta como eje contextual y formal de la técnica narrativa cervantina. En teoría y en práctica, se trata de un texto, como diría Richard Murphy, que «acusa su propia construcción» al mismo tiempo que «desbarata el proceso del realismo» (1999: 295).

Los consejos del amigo confirman que la novela se basa en un juego intricado de modelos y copias para desvalorar la realidad como concepto orientador y autoritario en la construcción de la novela. El prólogo hace patente que lo real deja de servir de objetivo de la percepción del mundo y de la representación del mismo. Estamos delante de «una literatura de plagio», en el sentido más posmoderno del concepto, de un texto que señala «el fin de la mimesis» y que «ha dejado de reflejar la naturaleza en el espejo y refleja sólo otros textos» (Broich, 1997: 252). El prólogo a la segunda parte de Don Quijote también alude a esta misma proposición posmoderna de imitar, jugar con, copiar y plagiar otros textos. Ha de recordarse que es en el segundo prólogo donde Cervantes arremete contra Gómez de Avellaneda por haber escrito un Quijote apócrifo y declara que es su propia novela la que genera, que da origen, a la segunda parte de la obra: «esta segunda parte de Don Quijote que te [lector] ofrezco es cortada del mismo artífice y del mismo paño que la primera» (Cervantes, 1970: 1489). Tampoco debemos olvidar el objetivo didáctico de Cervantes. La novela es, como bien se sabe, una parodia, «una invectiva contra los libros de caballerías» (1970: 1214). En resumidas cuentas, el acto creativo es el principio, método y fin de la novela de Cervantes y, por consiguiente, la razón de ser y estar y de vivir y morir de su protagonista, de los otros personajes y del propio texto.

Si los prólogos registran a nivel teórico la intención de Cervantes de crear una obra que existe por sí sola sin ninguna necesidad de apoyo en lo extraliterario, son las aventuras, batallas y encuentros de Don Quijote que revelan su objetivo a nivel textual. En las primeras aventuras de nuestro caballero andante y su escudero, la contienda entre lo real y lo ilusorio es sintomática de una lucha por imponer una sola perspectiva narrativa 
como ocurre en el episodio famoso y archiconocido de los molinos de viento. «En esto descubrieron», escribe Cervantes, «treinta o cuarenta molinos de viento que hay en aquel campo, y así como Don Quijote los vio, dijo a su escudero: La ventura va guiando nuestras cosas mejor de lo que acertáramos a desear; porque ves allí, amigo Sancho Panza, donde se descubren treinta o pocos más desaforados gigantes». La oposición de lo real y lo ilusorio está muy claramente delineada a principios de la novela: «eran molinos de viento, y no gigantes, aquellos que iba [Don Quijote] a acometer» (1970: 1241). Pero Don Quijote, a pesar de lo que le aconseja Sancho, insiste y las consecuencias de su obstinación son bien conocidas; la realidad se impone con una fuerza despiadada. El caballero arremete a todo el galope de Rocinante, embiste con el primer molino cuya aspa, al darse la vuelta, hace pedazos la lanza de Don Quijote el cual acaba rodando por el campo con Rocinante. Textualmente, la derrota del caballero señala que se trata de una escritura situada entre dos perspectivas narrativas en conflicto. Teóricamente, la yuxtaposición de molinos/gigantes anuncia la problematización contextual entre lo real y lo ficticio a que recurre Cervantes como mecanismo formal para desbaratar la jerarquía de la narrativa tradicional.

El encuentro con los frailes de San Benito se desarrolla de manera semejante, y con igual resultado. Se asoman «por el camino dos frailes de la orden de San Benito. [...] Detrás dellos venía un coche con cuatro o cinco de a caballo», y en el coche venía «una señora vizcaína». Al ver a los frailes, Don Quijote le declara a su escudero que «esta ha de ser la más famosa aventura que se haya visto; porque aquellos bultos negros [...] llevan hurtada alguna princesa en aquel coche» (Cervantes, 1970: 1243). De nuevo, Sancho le advierte de lo que se trata y le aconseja a su amo que «mire bien lo que hace» (Cervantes, 1970: 1243). Para probar que lo que dice es verdad, el caballero se aproxima a los frailes $\mathrm{y}$, declarando que llevan secuestradas a princesas en el coche, les pide que las liberen y arremete contra ellos. Cuando Sancho se dispone a ayudar a uno de los frailes, los mozos arremeten contra el escudero, dando «con él en el suelo y, sin dejarle pelo en las barbas, le molieron a coces y le dejaron tendido en el suelo, sin aliento ni sentido» (1970: 1244). La realidad sigue imponiéndose. Sin embargo, no paga Don Quijote, el responsable de distorsionar la realidad, sino Sancho, señal que lo fabricado en la imaginación de nuestro caballero conlleva consecuencias en el mundo ajeno.

$\mathrm{Al}$ encuentro con los frailes, le sigue el de Quijote con el vizcaíno. Como bien se sabe, Don Quijote conquista al vizcaíno al cual el caballero obliga a «ir al lugar del Toboso y presentarse» de su parte «ante la sin par doña Dulcinea del Toboso» (Cervantes, 1970: 1248). Lo que le obliga Don Quijote al vizcaíno testifica que la frontera entre la realidad y la ilusión ha sido desgastada lo suficiente para que un personaje firmemente arraigado en el mundo objetivo (el mundo de los molinos y de los frailes) desempeñe un papel fundamental en el mundo de la ilusión (el mundo de la caballería andante de Quijote). El mundo de la ilusión comienza a exhibir igual arraigo que el de la realidad, señalando una disolución de los dos. Como todo autor posmoderno, Cervantes se empeña en hacer aún más perpleja y compleja la relación y dinámica problemática entre texto e imagen y entre presentación y representación creando una mayor brecha entre el original y la copia (ver Blau, 1987: 189-205). Es un intento de desjerarquizar lo real frente a lo 
ilusorio. Pedirle al vizcaíno que vaya a Toboso a «presentarse [...] ante la sin par doña Dulcinea» presupone la construcción metaléptica de su personaje, un personaje capaz de traspasar la frontera que tan destacadamente había separado el mundo de los molinos y el de los gigantes para existir en los dos mundos simultáneamente. Por lo tanto, no sorprende que la confluencia de lo real y lo ilusorio se da en conjunción con la autoridad disminuyente del propio Cervantes frente a su obra como se señala mediante la narración truncada del encuentro entre el vizcaíno y Don Quijote. Listos para enfrentarse, leemos que «paró y quedó destroncada tan sabrosa historia, sin que nos diese noticia su autor dónde se podría hallar lo que della faltaba» (Cervantes, 1970: 1245).

Es precisamente aquí, como bien se sabe, donde se presenta a Cite Hamete Benegeli, un historiador musulmán que escribió gran parte del Quijote, lo cual señala la rendición de Cervantes como autoridad absoluta sobre su obra. El deterioro de la frontera entre lo real y lo ilusorio, la desaparición o muerte del autor y la autonomía del texto van de la mano como han demostrado Roland Barthes (1974: 65-71) y Michel Foucualt. La capacidad del vizcaíno de desempeñar un papel simultáneamente en el mundo de la realidad y de la ilusión es comparable a la situación de Cervantes como escritor que decide ceder su autoría narrativa a un texto escrito por un personaje ficticio. El escritor, tradicionalmente la única autoridad de la producción artística, está en crisis. Lo que comenzó como una relación contenciosa entre lo real (molinos) y lo ficticio (gigantes), entre la vida y el arte, acaba dando señal de desmantelar gradualmente la potencia inescrutable de la realidad, como diría, Debra Malina (2002: 25-62). La conquista del vizcaíno a manos de Don Quijote nos da a entender que la ilusión tiene igual capacidad de imponerse por sí sola y con autoridad. Como toda obra posmoderna, la novela de Cervantes desgarra las reglas de forma y contenido y asienta una transformación de suposiciones artísticas desde dentro de la propia novela.

Las aventuras que siguen subrayan la auto-generatividad de la novela. El episodio del Cuerpo Muerto, por ejemplo, se contextualiza por una perspectiva narrativa en transición. Es de noche cuando a Quijote y a Sancho les sucedió, según escribe Cervantes, «una aventura, que, sin artificio alguno, verdaderamente lo parecía. [...] Vieron que por el mesmo camino que iban venían hacia ellos gran multitud de lumbres, que no parecían sino estrellas que se movían» (1970: 1286). Por primera vez, a Sancho -y por cierto a los lectores- le llega la escena desde la misma perspectiva que Don Quijote, una perspectiva que esquiva la realidad a favor de la fantasía. Temblando de miedo, el escudero hace eco de las palabras con las cuales su amo habló de encuentros previos: «si acaso esta aventura fuese de fantasmas como me la va pareciendo» (Cervantes, 1970: 1287).

La línea entre lo real y lo ilusorio se ha obscurecido. El mundo imaginado de y añorado por Don Quijote da señales de haberse fusionado con el mundo objetivo de Sancho. En la aventura del Cuerpo Muerto, la realidad no se yuxtapone al mundo quijotesco imaginado. Aquí lo percibido como realidad compagina con el mundo caballeresco. «Esta extraña visión», escribe Cervantes, «bien bastaba para poner miedo en el corazón de Sancho y aun en el de su amo» para quien «aquella era una de las aventuras de sus libros» (1970: 1287). Cuando Quijote quiere parar a los caballeros encamisados, éstos no quieren detenerse y proporcionarle al caballero la información que les pide por lo cual se enfurece 
y les grita. Una mula se asusta y tira al suelo a su dueño. Todos los hombres huyen menos el que está en el suelo. Cuando éste le explica a Don Quijote que los encamisados son gente de paz sin armas, Don Quijote le pide perdón y con la ayuda de Sancho el hombre se pone sobre su asno para que pueda seguir a sus compañeros.

Si el objetivo del arte posmoderno es, como dice Simon Malpas, «presentar el mundo como una entidad en constante estado de mutación y metamorfosis» (2005: 31), entonces el mundo que crea Cervantes en Don Quijote es posmoderno. Don Quijote no entra en batalla ni se venga como hubiera querido. Pero desde la perspectiva de la narrativa, el episodio comienza y termina con lo que alimenta su mundo. La dicotomía realidad/ ilusión (molino/gigante) no se da al principio de la aventura, ni al final. En el episodio del Cuerpo Muerto, la realidad y la ilusión, el mundo de Don Quijote y el mundo de Sancho, son durante un tiempo uno y el mismo. No se distingue entre realidad y ficción, lo cual apunta al uso ontológico del perspectivismo narrativo por parte de Cervantes.

Lo mismo pasa en el próximo capítulo cuando lo primero que se cuenta es que el caballero y su escudero «oyeron que daban unos golpes a compás, con un cierto crujir de hierros y cadenas, acompañados de furioso estruendo del agua» (Cervantes, 1970: 1290). Igual que la aventura del Cuerpo Muerto, la escena engendra miedo: «de manera, que la soledad, el sitio, la escuridad, el ruido del agua con el susurro de las hojas, todo causaba horror y espanto» (Cervantes, 1970: 1290). Se trata, como dice el mismo Sancho, de una «temerosa aventura» (Cervantes, 1970: 1291). Otra vez, lo real y lo fantaseado se han fusionado. Es sólo la próxima mañana cuando se averigua que el ruido eran batanes. La realidad tarda en averiguarse, permitiendo que la ilusión persista en la mente de todos. Igual que el episodio del Cuerpo Muerto, el de los batanes, como diría Brian McHale, «disturba sistemáticamente el aire de la realidad poniendo de relieve la estructura ontológica del texto y del mundo ficticio» (1987: 221). Se trata de dos episodios con potencial de ser aventuras auténticas, no de una realidad trasformada en ilusión por nuestro caballero, como en el caso de los molinos. Lo real y lo ilusorio, la vida y el arte se van fundiendo para presentarse como uno.

El episodio del Cuerpo Muerto y de los batanes reflejan una trasgresión de niveles ontológicos que se va manifestando con creciente insistencia como en el episodio del yelmo de Mambrino. El episodio se presenta de manera igual que el de los molinos y de los frailes, con lo real y lo ilusorio en oposición. «Hacia nosotros», como dice Don Quijote, «viene uno que trae en su cabeza puesto el yelmo de Mambrino». Pero Sancho ve a «un hombre sobre un asno, pardo como el mío, que trae sobre la cabeza una cosa que relumbra» y que «como comenzó a llover [...] se puso la bacía sobre la cabeza» (Cervantes, 1970: 1298). El episodio de los Galeotes que sigue inmediatamente al del Yelmo de Mambrino responde al patrón de las aventuras del Cuerpo Muerto y de los batanes. Se presentan como auténticas aventuras: «Don Quijote alzó los ojos y vio que por el camino que llevaba venían hasta doce hombres a pie, ensartados [...] en una gran cadena de hierro, por los cuellos, y todos con esposas a las manos» (Cervantes, 1970: 1304). Lo presentado nos llega mediante una lente literaria, los libros de caballería en cuya lectura Don Quijote «se enfrascó tanto» que «se le pasaban las noches leyendo de claro en claro y los días de turbio en turbio» (Cervantes, 1970: 1220). Son galeotes, 
como bien confirma Sancho y, por ende, auténticos personajes de una aventura caballeresca.

Los episodios del yelmo de Mambrino y de los galeotes son recordatorios de la tensión narrativa entre lo real y lo ilusorio que fundamenta la novela de Cervantes y que lo fantaseado es capaz de imponerse como única lente mediante la cual se percibe el mundo. El objetivo de Cervantes es cuestionar la idea de una realidad fija y absoluta como objeto de nuestra percepción y refutar la idea de un «una verdad subyacente permanente y duradera», para citar a Stanley Grenz (1996: 27). Los episodios del yelmo de Mambrino y de los galeotes ilustran que no hay absolutos en la novela. En ningún momento se demuestra mejor dicha hipótesis que en los capítulos 44-45 de la primera parte cuando reaparece el barbero, decidido a recuperar su bacía de que le había arrebatado Don Quijote.

Se discute si el famoso yelmo de Mambrino es yelmo o una simple bacía, «baciyelmo» como lo llama Sancho (Cervantes, 1970: 1446). También se discute si es albarda o jaez la otra pertenencia que le fue quitada al barbero. Cuando el barbero del supuesto yelmo invita la opinión de los otros que están presentes en la venta, el barbero Nicolás se jacta de ser del mismo oficio que él y declara que «remitiendo siempre al mejor entendimiento, que esta pieza que está aquí delante [...] no solo no es bacía de barbero, pero está tan lejos de serlo como está lejos lo blanco de lo negro» y termina por declarar que «es yelmo», aunque «no yelmo entero» (Cervantes, 1970: 1447). Se decide resolver la confusión entre la albarda y el jaez tomando votos en secreto de los que están presentes. Pero cuando uno de los cuadrilleros de la Santa Hermandad declara que «tan es albarda como mi padre» (Cervantes, 1970: 1448), Don Quijote se enfada y se dispone a descargarle un golpe con su lanza, lo cual acaba convirtiendo la venta en una confusión de «llantos, voces, temores, sobresaltos, desgracias, cuchilladas entre los que decía que era jaez y los que decían que era albarda» (Cervantes, 1970: 1449).

Para Cesareo Bandera, el debate sobre la bacía y el yelmo encapsula la problemática de toda la novela de Cervantes. El baciyelmo, escribe Bandera, igual que la novela, oscila entre «la afirmación y la negación» de la realidad y la ficción, conceptos que intercambian «sus respectivas posiciones sin coincidir jamás en el mismo punto» y que son «siempre iguales e incompatibles» (1974: 168). La realidad en Don Quijote no es un concepto estable sino movedizo; es un concepto que evita la percepción unificada. Representar un mundo que vacila «entre diferentes tipos y grados de realidad» y que niega «la realidad de un mundo unificado como objeto de nuestra percepción», como escriben McHale (1987: 232) y Grenz, (1996: 40), respectivamente, son coordenadas céntricas y definitorias del arte posmoderno.

Se trata de una bacía que todos deciden aceptar como yelmo. Por lo tanto, es bacía y yelmo y no es ni bacía ni yelmo al mismo tiempo, enigma posmoderno por excelencia que encapsula el dilema ontológico de todo el mundo cervantino. Lo mismo pasa con el jaez que es jaez para unos y albardo para otros. La discusión sobre el yelmo y el jaez afirman que la realidad es relativa, indecisa y modificable y que se hace, se genera, al andar. Ambos episodios reiteran la contextura posmoderna de la novela cervantina, un mundo que, para citar a Hans Bertens, «rechaza la causalidad y la consistencia» (1987: 139) para pintar un mundo esencialmente «pluralista» (1987: 142). 
En un mundo donde se discute, se debate y se negocia lo que constituye la realidad, lo ilusorio no tarda en imponerse como única fuente creadora como se sugiere hacia finales del capítulo 45: «Finalmente, el rumor se apaciguó por entonces, la albarda se quedó por jaez hasta el día del juicio, y la bacía por yelmo y la venta por castillo en la imaginación de don Quijote» (Cervantes, 1970: 1449). Que lo ilusorio esté firmemente arraigado en la imaginación de Don Quijote no sorprende. Pero lo que transcurre en la venta sugiere que lo ilusorio se ha arraigado en el mundo ajeno como medio y fin artístico señalando la secesión definitiva de la autoridad narrativa del propio Cervantes sobre su texto.

No es coincidencia que Cervantes retome la idea de la muerte del autor en un capítulo anterior a los en que se discute el yelmo y el jaez, precisamente en el capítulo 40 en que se cuenta la historia del capitán cautivo y en el cual el novelista se inserta en su propia obra: «Solo libró bien con él un soldado español, llamado tal de Saavedra, al cual, con haber hecho cosas que quedarán en la memoria de aquellas gentes por muchos años, y todas por alcanzar la libertad, jamás le dio palo, ni se lo mandó dar, ni le dijo mala palabra» (Cervantes, 1970: 1417). El elemento biográfico aparte, al injertarse en su propia novela, Cervantes se ficcionaliza y así ocupa el mismo mundo de sus personajes, un mundo desprovisto de autoridades absolutas. Su intención es romper efectivamente con la idea del escritor como poder creativo extratextual para situar la autoridad narrativa dentro de los confines de la propia novela. Se trata de rechazar el realismo narrativo, que tradicionalmente recalca la autenticidad y la experiencia, y adoptar un modelo desconstructivista de la presentación y representación artística como procesos auto-suficientes y auto-generadores, lo cual es más persistentemente evidente en la segunda parte de la novela.

En la primera aventura de la segunda parte, Quijote y Sancho van camino de Zaragoza conversando tranquilamente cuando se les aparece «una carreta [...] cargada de los más diversos y extraños personajes y figuras que pudieron imaginarse». «El que guiaba las mulas y servía de carretero», continúa la narración, «era un feo demonio» y «la primera figura que se ofreció a los ojos de Don Quijote» -y los de Sancho y los lectores- «fue la de la muerte». No se tarda mucho en averiguar que se trata de una compañía de teatro que acaba de representar «Las Cortes de la Muerte» en un pueblo cercano. Pero no antes de dejar claro que lo que se les presenta al caballero y su escudero en mitad del camino es una verdadera «nueva y peligrosa aventura» (Cervantes,1970: 1527). El concepto de la teatralidad relacionado con este episodio, y en particular su presentación, profundizan la contextura posmoderna del Quijote.

En lo que se refiere a «Las Cortes de la Muerte», hay una afirmación de la contienda entre presentación y representación que fundamenta la técnica narrativa cervantina. El episodio constituye un dilema ontológico conspicuo. Conspicuo porque se trata de una confrontación de dos mundos ficticios pero de igual poder, el inventado de Cervantes y el inventado de la función teatral. «La teatralidad», nos recuerda Steven Connor, «está conectada con las mayores preocupaciones del debate posmoderno» porque toda obra teatral ejemplifica, según Connor, «la tensión entre el producto y el proceso» (1997: 142). El encuentro con la compañía de actores rechaza la narrativa tradicional, como diría Connor, porque "presenta en vez de representar» (1997: 149). A diferencia de las primeras aventuras, lo que se presenta acercándoles a Quijote y Sancho es indistinguible de la 
propia ficción que ellos mismos viven. Es una escena que duplica y multiplica el mundo de la ilusión textual y contextualmente, lo cual sugiere que Quijote y Sancho, y los otros personajes de la novela, se encuentran en un mundo de ficción siempre más autoritario y recurrente que sustituye la realidad. Como todo texto posmoderno, la novela de Cervantes «no se propone superar la separación de arte y vida» (Schulte-Sasse, 1987: 7). Esto viene reafirmado posteriormente $-\mathrm{y}$ notablemente, otra vez en un contexto teatral- en el episodio del retablo del Maese Pedro, en el capítulo 26, donde presentar la ilusión y la realidad es uno y lo mismo.

Este dilema ontológico también se exhibe en el encuentro de Don Quijote con el Caballero de los Espejos (también del Bosque). Como bien se sabe, el Caballero de los Espejos es Sansón Carrasco. En su papel de caballero andante, el bachiller afirma haber vencido a muchos caballeros, entre ellos al gran Don Quijote de la Mancha. Sansón persiste en su mentira por lo cual Don Quijote le reta a un duelo y lo vence. El intento de Sansón de ponerse caballero profundiza a nivel de personaje la misma escisión discursiva encerrada en el baciylemo pero con más insistencia en la auto-generatividad de la narración cervantina inicialmente sugeridass por el encuentro con los actores de «Las Cortes de la Muerte».

Si Don Quijote es una figura cuyo nacimiento y razón de ser se deben a las incesantes lecturas nocturnas de un aldeano Alonso Quijano, la figura del Caballero de los Espejos es una figura cuyo nacimiento y razón de ser se deben a la lectura de la primera parte del Quijote. La decisión de Sansón de meterse caballero y ganar acceso al mundo fantaseado de Don Quijote -al mismo que ganó acceso Cervantes- nos recuerda lo que nos dice Broich de los personajes posmodernos: «Los personajes posmodernos no viven en textos que imitan nuestro mundo sino en textos que imitan otros textos» (1997: 253). Situarse Cervantes en su propio texto como personaje al lado de otros personajes de ficción y adoptar Sansón Carrasco la identidad de caballero tomando como modelo al propio Don Quijote ilustran que el arte y la vida son procesos de retextualización y reapropiación esencialmente auto-reflexivos. En un mundo donde se debate la autoridad de lo real, existir es la función resultado de vivir el arte, no de experimentar la realidad. Ya no son la realidad y la vida que sirven como fuentes del arte sino la ilusión y el arte que sirven como fuentes de la vida. Dicha observación, como insistí al principio del ensayo, no constituye una nueva valoración crítica de la novela de Cervantes. Juan Bautista AvalleArce ya lo había dicho en 1976: «el hidalgo manchego [...] se empeñó en vivir la vida como una obra de arte» (212). Sin embargo, volver al estudio de la dinámica operativa entre lo real y lo ilusorio en el Quijote más de tres décadas después adoptando teorías literarias de la época posmoderna actual reafirma que lo que propone Cervantes en Don Quijote está siempre vigente.

El Caballero de la Blanca Luna constituye una mise-en-abyme a nivel de personaje. Definida por Richard Cardwell como «una serie de espacios conceptuales y estructurales que se superponen infinitamente y forman un tipo de laberinto cuyo centro o núcleo se mueve constantemente y que es imposible alcanzar» (1989: 271), toda mise-en-abyme tiene como objetivo último recalcar la pérdida de todo absoluto. En Don Quijote, Cervantes (con)funde ilusiones para descentralizar su novela y despojarle de un centro o un nú- 
cleo orientador. La decisión de Sansón de meterse caballero andante es una reproducción de un mundo de ficción dentro de otro lo cual, como diría Anne Jefferson, «no cancela» completamente la realidad pero sí «la suspende» temporalmente (1983: 198). Meterse caballero Sansón es sintomático de un mundo en que la realidad ha perdido su valor elemental constitutivo, constructivo y orientador frente a la vida. A diferencia de Alonso Quijano, para Sansón ser arte y vivir arte son lo mismo.

En un mundo donde se descarta la realidad, lo ilusorio se establece como la única autoridad, hipótesis ejemplificada en los personajes del duque y la duquesa. Los duques son figuras que gozan de igual poder textual, contextual, y narrativo en el mundo de la realidad objetiva (Alonso Quijano, Sansón, el cura, la sobrina, etc.) que en el mundo de la ilusión (Don Quijote, los gigantes, Montesinos, Malambruno, el Caballero de los Espejos, etc.). Si la nomenclatura en el caso del baciylemo encarna la subyacente fricción y dicotomía del mundo de la novela de Cervantes y el primer intento de Sansón de meterse caballero representa un deseo de violar la línea divisoria entre la realidad y la ilusión, los duques son la evidencia que la frontera entre lo real y lo ilusorio ha desparecido.

Los duques son personajes textual y contextualmente propios del mundo de la caballería que reafirman su existencia en la novela de Cervantes. En las palabras de McHale, «la presencia de tales figuras viola la frontera entre el mundo real y el mundo ficticio con fines decisivamente ontológicos» (1987: 85). La metalepsis que comenzó con el vizcaíno a principios de la novela termina con los duques. La realidad objetiva ni sirve ni es necesaria para explicar el origen de los duques ni su razón de ser. Son personajes que provienen de y subsisten en el mundo caballeresco real y del caballeresco fantaseado al mismo tiempo y mediante cuya existencia el arte se celebra como artífice y como vida.

Tanto es el caso que lo artístico da con consecuencias tangibles y concretas en la realidad: la gobernación de la Isla Barataria de Sancho. Realidad incontestable, la isla también es producto de un proceso artístico independiente y auto-suficiente, de un proceso narrativo auto-generador. En los libros de caballería no se oye mencionar que a un escudero se le hace gobernador de una isla, como nos recuerda el propio Quijote. La isla de Sancho no tiene precedencia textual ni contextual. Llega a ser por sí misma, lo cual señala, como diría Ihab Hassan, la total y completa «descanonización» de la realidad frente a la representación artística (1987: 19). La Isla Barataria es una realidad que se forja autónomamente. Lo mismo se puede decir cuando reaparece Sansón Carrasco como caballero andante.

La primera vez que aparece Sansón como caballero andante, se presenta recalcando su profesión pero sin nombrarse. «Caballero, soy», dice (Cervantes, 1970: 1532). En su segunda aparición, el bachiller no vacila en anunciarle a Don Quijote quién es y por qué ha venido. «Yo soy el Caballero de la Blanca Luna» (Cervantes, 1970:1741) y «Vengo a contender contigo» (Cervantes, 1970: 1742). Igual que Don Quijote al principio de la novela, Sansón se auto-nombra, se auto-crea creando otra mise-en-abyme. En el caso de Alonso Quijano, se trata de un personaje que proviene de un mundo real objetivo para cobrar significado en un mundo de ficción. En el caso de Sansón, se trata de un personaje que proviene de un mundo de ficción para insertarse en otro mundo de ficción. Dicho sencillamente, el Caballero de la Blanca Luna se crea de la nada. 
«El acto de nombrar», es según Thomas Docherty, «asentar y afirmar la totalidad de la existencia de uno» (1983: 50). «El nombre», continúa Docherty «indica cierta autoridad ontológica sobre la constitución del ser» (1983: 73). En su segunda aparición cuando el Caballero de la Blanca Luna se auto-nombra, Sansón acaba por concretar su existencia en un mundo de ficción y así reafirma la auto-generatividad de la narrativa cervantina. Empezando con la fuerte y conflictiva oposición entre la realidad y la ilusión, inicialmente presentada en el episodio de los molinos, progresando hacia la confluencia de lo real y lo ilusorio, simbolizada en el baciylemo, y terminando con la ficción como motor generador, encarnado en el Caballero de la Blanca Luna, se pone fin a la desconstrucción de la realidad, a su desjerarquización como fuente y autoridad de la creación artística. Lo que comenzó como una interacción vital entre la realidad (Alonso Quijano) y la ficción (Don Quijote) termina como una interacción vital entre ficciones (Sansón y el Caballero de la Blanca Luna). La realidad ha desparecido, y «todo lo que queda», para citar a Jean Baudrillard, «son simulaciones» (1988: 170). La Isla Barataria y el personaje del Caballero de la Blanca Luna son la mayor evidencia que en el Quijote, como en toda obra posmoderna, «la realidad no precede el texto sino que es el efecto, el producto, el resultado del texto» (Lucy, 1997: 14). El mundo que pinta Cervantes en Don Quijote es un mundo construido por la intersección de ficciones y sostenido por esa misma intersección, un mundo de interminable sondeo ontológico.

La derrota de Don Quijote a manos del Caballero de la Blanca Luna al final de la novela, su subsiguiente regreso a casa y su muerte es la señal definitiva que la realidad ha desvanecido, consecuencia del fuerte poder generador del arte. La ilusión y el arte -en el personaje del Caballero de la Blanca Luna- han ganado a la realidad y a la vida. Aunque parece que la realidad se reimponga en el último capítulo cuando nuestro caballero anuncia que «ya no soy Don Quijote de la Mancha sino Alonso Quijano el Bueno» (Cervantes, 1970: 1770), la referencia a Sancho como «el buen escudero Sancho Panza» y la propia insistencia de éste que no se muera su amo y que se levante de su cama y que se vayan al campo «vestidos de pastores, como tenemos concertado» (Cervantes, 1970: 1771) sugiere que lo ilusorio se ha implantado como el único poder creativo de la narración cervantina. Lo que comenzó con un personaje de la realidad obsesionado por vivir una ilusión (Quijano), termina con personajes de esa misma ilusión vivida (Sansón y Sancho) que invocan otra ilusión para seguir viviendo, prueba definitiva de la auto-generatividad de la novela cervantina y, por lo tanto, de su innegable contextura posmoderna y su perenne vigencia temática, teórica y crítica cuatro siglos después de su publicación.

\section{BIBLIOGRAFÍA}

Avalle-Arce, J. B. (1976): ‘Don Quijote’ como forma de vida. Madrid: Fundación Juan March.

Bandera, C. (1974): «Cervantes frente a Don Quijote: Violenta simetría entre la realidad y la ficción». En: Modern Language Notes, 89, 2, 159-172. 
Barthes, R. (1968): El susurro del lenguaje. Más allá de la palabra y la escritura. Barcelona: Paidós.

Baudrillard, J. (1988): Jean Baudrillard: Selected Writings. Mark Poster (ed.). Stanford: Stanford University Press.

Bertens, H. (1987): «Postmodern Characterization and the Intrusion of Language». En: Douwe Fokkema y Matei Calinescu (eds.), Exploring Postmodernism. Amsterdam: John Benjamins, 139-159.

Beusterien, J. (2006): «Reading Cervantes: A New Virtual Reality». En: Comparative Literature Studies, 43,4, 428-440.

Blau, H. (1987): The Eye of Prey: Subversiones of the Postmodern. Bloomington: Indiana University Press.

Broich, U. (1997): «Intertextuality». En: Hans Bertens y Douwe Fokkema (eds.), International Postmodernism: Theory and Literary Practice. Amsterdam: John Benjamins, 249-255.

Cardwell, R. A. (1989): «Beyond the Mirror and the Lamp: Symbolist Frames and Spaces». En: Romance Quarterly, 36, 3, 271-280.

Cervantes, M. de (1970): El ingenioso hidalgo Don Quijote de la Mancha. Obras completas. Ángel Valbuena Prat (ed.). Madrid: Aguilar, 1211-1773.

Connor, S. (1997): Postmodernist Culture. An Introduction to Theories of the Contemporary. Cambridge: Blackwell Publishers, 1997.

Docherty, T. (1983): Reading (Absent) Character. Towards a Theory of Characterization in Fiction. Oxford: Clarendon Press.

Dunn, P. (2004): «Contested Discourses in Don Quijote, Part Two». En: Bulletin of Spanish Studies: Hispanic Studies and Researches on Spain, Portugal, and Latin America, 81, 4-5, 501-514.

Durán, M. y Fogg, F. R. (2006): Fighting Windmills. Encounters With Don Quixote. New Haven: Yale University Press.

Foucault, Michel. (1968): «Qu’est-ce qu’un auteur?» Bulletin de la Societé française de Philosophie, 64, 73-104.

Gabriele, J. P. (2005): «Narrative Prisms and Prisons: Mirror Effects and mise-en-abyme in Don Quijote». Symposium, 29, 1, 31-42.

Grenz, S. J. (1996): A Primer on Postmodernism. Grand Rapids: William B. Eerdmans Publishing.

Hassan, I. (1987): «Pluralism in Postmodern Perspective». En: Matei Calinescu y Douwe Fokkema (eds.), Exploring Postmodernism. Amsterdam: John Benjamins, 1987, 17-39.

Jefferson, A. (1983): «Mise-en-abyme and the Prophetic in Narrative». En: Style, 17, 2, 196-208.

Lucy, N. (1997). Postmodern Literary Theory. An Introduction. Oxford: Blackwell.

Malina, D. (2002): Breaking the Frame: Metalepsis and the Construction of the Subject. Columbus: Ohio State University Press.

Malpas, S. (2005): The Postmodern. New York: Routledge.

McHale, B. (1987): Postmodern Fiction. London: Methuen. 
Murphy, R. (1999): Theorizing the Avant-Garde. Modernims, Expressionism, and the Problem of Postmodernity. Cambridge: Cambridge University Press.

Ramírez, Á. (2005): «Don Quijote and the Age of Simulacra». En: Hispania, 88, 1, 82-90.

Ramírez, Á. (2006): «Counterdefinitions of Reality: Translating the World in Don Quijote de la Mancha». En: Comparative Literature Studies, 43, 4, 414-427.

Riley, E. C. (2005): «Literature and Life in Don Quijote». En: Roberto González Echevarría (ed.), Cervantes” «Don Quijote»: A Casebook. New York: Oxford University Press, 125-140.

Schulte-Sasse, J. (1987): «Modernity and Modernism, Postmodernity and Postmodernism: Framing the Issue». Cultural Critque, 5, 5-22.

Tollinchi, E. (2007): «El gusanillo de la realidad en El Quijote». En: Torre: Revista de la Universidad de Puerto Rico, 12, 43, 37-48.

Weber, A. P. (1999): «The Ideologies of Cervantine Irony: Liberalism, Postmodernism and Beyond». En: Anne J. Cruz y Carroll B. Johnson (eds.), Cervantes and His Postmodern Constituencies. New York: Garland, 218-234.

\section{NARATIVNA AVTOGENERATIVNOST V DON KIHOTU: PARADIGMA POSTMODERNE LITERARNE KONVENCIJE}

Ključne besede: resničnost, iluzija, avtogenerativnost, postmoderna

$\mathrm{Z}$ vidika postmoderne literarne teorije je Don Kihot roman, v katerem si resnično in iluzorno vztrajno nasprotujeta, se izzivata, spajata in mešata ter tako sugerirata, da sta umetnost in življenje predvsem avtorefleksivna procesa retekstualizacije in reapropriacije. Pri analiziranju Cervantesovega romana problematika odnosa med resničnostjo in iluzijo ni nova tema. Toda proučevanje dinamike med resničnim in iluzornim vendarle ostaja najučinkovitejši kritični pristop, ki priča o večni sodobnosti tega dela. Dejstvo, da za analiziranje transcendenčnega operativnega odnosa med realnim in iluzornim v Cervantesovem romanu ter za dokazovanje, kako je avtorju uspelo ustvariti besedilo, ki se samorazvija (avtogenerira), uporabljamo današnje postmoderne literarne teorije, namreč poudarja, da je Don Kihot tematsko, teoretsko in kritiško večno sodobno besedilo. 